\title{
UTILIZAÇÃO DE UMA TÉCNICA RÁPIDA PARA O DIAGNÓSTICO DE MYCOBACTERIUM BOVIS EM AMOSTRASDE LEITE EXPERIMENTALMENTE INOCULADAS
}

\section{C.C. Dibis , Z.M . M orais², G .0. de Souza², M. Amaku², N.R. Benites², S.R. Pinheiro²}

Instituto de Zootecnia, Rua Heitor Penteado 56, CEP 13460-000, Nova Odessa, SP, Brasil. E-mail: corsi@iz.sp.gov.br

RESUMO

O mei o de Middlebrook $7 \mathrm{H} 11$ modificad o foi comparado ao meio de Stonebrink, a fim dese avaliar a sensibilidade e tempo dedetecção demicobactérias em amostras deleite, experimental mente inoculadas com M y cobacteriu m bovis (estirpe AN 5), em uma diluição $10^{2}$, esubmetidas a duas diferentes técnicas de processamento: gordura (técnica 1) e sedimento (técnica 2), descontaminadas pelo método de Petroff modificado (adicionado de Tween 80), confrontadas com a técnica do leite total submetida ao método de Petroff tradicional. Os resultados destas técnicas (1e2) foram comparados entresi pelos testes não paramétricos deWilcoxon edeM annWhitney edemonstraram queas técnicas le 2 forneceram maior recuperação demicobactériase proporção de cultivos positivos nos meios de Stonebrink e Middlebrook 7H 11; o meio de Middlebrook $7 \mathrm{H} 11$ permitiu a visualização precoce das micobactérias, podendo ser utilizado como uma técnica de diagnóstico rápida da tuberculose bovina, em amostras de leite, para fins de vigilância epidemiológica.

PALAVRAS-CHAVE: Tuberculose, M ycobacterium bovis, leite, Middlebrook, isolamento.

\section{ABSTRACT}

UTILIZATION OFTHEFASTISOLATION TECHNIQUE OFMYCOBACTERIUM BOVISFROM EXPERIMENTA LLY INOCULATED MILK SAMPLES.Themodified Middlebrook 7H 11cultivation techniquewas compared with thetradicional culturetechniqueby using theStonebrink medium. The purpose of this comparison was to to eval uate the sensitivity and the time for the detection of positivecultures of mycobacteriain milk samplesexperimentally inoculated withM ycobacterium bovis (strain AN 5), ata dilution of $10^{-2}$, and submitted to twotypes of procedures: techniquel(skin milk) and technique2 (pellet), decontamined by modified thePetroff'smethod, added with Tween 80 , and compared with total milk samples submitted to tradicional Petroff method in the same mediatypes. Theresults of thetwo tecniqueswerecompared with each other by thenon-parametric Wilcoxon test and Mann-Whitney. The results obtained from this experiment showed that: techniques 1 and 2 produced great number of colonies and higher proportion of positiveculture than the tradicional one by using total milk; the time needed for the detection of mycobacteria colonies was sl ightly shorter by thethin layer techniquethan by thetradicional culturemethod; in order to improve the epidemiological surveillance, this technique should be used as a complementary method to thetradicional onein the diagnosis of bovinetuberculosis.

KEY WORDS:Tuberculosis, M ycobacterium bovis, milk, Middlebrook, isolation.

\section{INTRODUÇÃO}

A obrigatoriedadedapasteurizaçãodoleiteemnosso país estabeleceu-se em 1952 (BRANDÃo, 1994), entretanto, aindahojeseacreditaqueaproximadamente $50 \%$ detodo oleiteconsumidonoBrasil, nãoépasteurizado, aumentando orisco deinfecção por M ycobacterium bovis (LeiTE et al., 2003) ereafirmando a necessidade de políticas públicas que estabeleçam medidas de controle sanitário do leite (Antunes et al., 2002).

O Programa Nacional de Controle e Erradicação daBruceloseedaTuberculoseA nimal (PNCEBT), que

Universidade de São Paulo, Facul dade de M edicina Veterinária e Zootecnia, Departamento de M edicina Veterinária Preventiva e Saúde A nimal, São Paulo, SP, Brasil.

*Auxílio Bolsa Capes 
entrou em vigor no Brasil em 2001, estabeleceo testede tuberculinacomoaprincipal ferramentanodiagnóstico da infecção no bovino. Recomenda também o diagnóstico laboratorial que é importante na confirmação dos exames realizados no campo e/ ou frigorífico por favorecer o isolamento etipificação das cepas circulantes, informações estas importantes no processo decontrole eerradicação da doença (PN CEBT, 2001).

Dopontodevistadiagnóstico, umadasprincipais desvantagens da cultura de micobactérias éo tempo necessário entrea semeadura eo surgimento decolôniasmacroscopicamentevisíveis, oquelevade24a 40 dias em média (Koneman et al., 2001). O aperfeiçoamento do método microbiológico convencional para umrápidodiagnóstico representaumagrandevantagem na luta contra a tuberculose no homem e no bovino (MEJIA et al., 1999) etem considerável impacto no controle da doença no bovino (CORnER, 1994).

MejIA et al. (1999) e SMoskovi \& Magyar (1999) demonstraramasvantagens do diagnóstico datécnica de camada del gada que se baseia na observação precocedemicrocolôniasdemicobactériasem placas comumafina camada demeio deMiddlebrook $7 \mathrm{H} 11$, frente ao método tradicional de cultivo em meios de Löwenstein-Jensen eStonebrink. Esses trabalhos demonstramsignificativareduçãonotempo paraobservação das primeiras colônias com el evada sensibilidadeemfavor datécnica decamadadelgada, alémde permitir aidentificação preliminar dasmicobactérias por suas características morfológicas.

Os métodos utilizados para descontaminação de amostras deleite"in natura" jáforamobjeto dediscussão no meio acadêmico (PARdo et al ., 2001; Perezet al ., 2002) eatéhoje, não háum método dedescontaminação específico para o leite. Na prática laboratorial de isolamento de micobactérias no leite, a fração da gordura do leite obtida após o processo de centrifugação das amostras, é descartada, utilizando-seapenas do sedimento no processamento destas amostras (PARdo et al ., 2001; Perez et al ., 2002; KANTOR, 1976; Dunn \& Hodgson, 1982). A elevada concentração de lipídios da parede cel ular das micobactérias (Koneman et al., 2001) poderia fazer com que a sua presença em amostras de leite, possivelmente associadasàgorduradoleite, passassedespercebida, devido ao descarte desta fração obtida por meio da centrifugação das amostras, diminuindo desta maneira a sensi bilidade da técnica diagnóstica.

Este trabal ho foi delineado para investigar a viabilidadetécnica deum método dediagnóstico rápido para o M. bovis, a partir de amostras de leite "in natura", assim como testar sua eficiência quando comparado com os métodos de cultura tradicionais usando como inóculo amostras descontaminadas pela técnica de Petroff modificada pela adição do Tween.

\section{MATERIAL E MÉTODOS}

Foi realizada inicialmente, uma suspensão bacteriana de $M$ ycobacterium fortuitum, a partir da suspensão de $0,06 \mathrm{~g}$ decolônias (peso úmido) raspadasdasuperfíciedo meio, com32diasdecrescimento no meio de Petragnani, em $1 \mathrm{~mL}$ de solução salina 0,85\% com 0,05\% de Tween 80 (polioxietilensorbato monooleato) (PINHEIRo et al. 1997), para padronizar os melhores parâmetros de diluição a serem preconizados posteriormente, e semeado no meio de Middlebrook 7H 10 (CENTRO PANAMERICANODE ZOONOSIS, 1979). Para estefimforam realizadas diluições del:1; 1:10 e 1:100. Com a diluição estabelecida, nas fases seguintes, os inóculos passaram a ser preparados com M . bovis (estirpeA N5), com 32 dias decultivo no meiodeStonebrink (Centro PanamericanodeZoonosis, 1979).

As amostras deleiteforam obtidas em umaúnica ordenha, deum animal clinicamentesadio, negativo ao teste de tuberculina e ao California M astitis Test (CMT). Todas as alíquotas de $4,5 \mathrm{~mL}$ foram mantidas a $-20^{\circ} \mathrm{C}$ atéo dia do processamento.

Procurou-se verificar se ocorria diferença no número de micobactérias recuperadas das diferentes fases do leite, gordura (técnica 1) esedimento (técnica 2), obtidos por meio da centrifugação das amostras, e avaliar o período mínimo em dias, necessário para o crescimento das U.F.C. (Unidades Formadoras de Colônias) apósa semeadura nosmeios deStonebrink e Middlebrook $7 \mathrm{H} 11$ modificado. O procedimento desta etapa baseou-se em: a cada amostra de $4,5 \mathrm{~mL}$ de leite descongelado foi adicionado $0,5 \mathrm{~mL}$ da suspensão bacteriana na diluição $10^{-1}$, homogeneizada em aparelho tipo Vortex, resultando em amostras de diluição $10^{-2}$. Foram efetuadas 30 repetições, sendo quecada amostra utilizada foi subdividida em duas outras amostras obtidas por meio de centrifugação a 3.000 rpm por $20 \mathrm{~min}$, obtendo-sedestaforma as duas fases doleite: gordura(técnica 1) esedimento (técnica 2) acondicionadas em frascos diferentes e comparadas a técnica tradicional de leite total submetida a descontaminação de Petroff. Tanto à gorduraquanto ao sedimento, foi adicionado $1 \mathrm{~mL}$ desolução salina contendo $0,05 \%$ de Tween 80 , seguida da homogeneização em aparel ho Vortex, esubmissão à centrífuga por $3.000 \mathrm{rpm}$ por $20 \mathrm{~min}$. A pós o descarte do sobrenadante, ressuspendeu-seo sedimento com $1 \mathrm{~mL}$ de solução salina $0,85 \%$ e realizou-se a descontaminação pela técnica de Petroff. Ao final deste procedimento foram semeadas duas placas contendo meio Middlebrook $7 \mathrm{H} 11$ e dois tubos contendo meioStonebrink paraas trêstécnicas empregadas (técnicas 1, 2 e técnica tradicional).

As placas foram incubadas a $37^{\circ} \mathrm{C}$, em condições de microaerofilia, dentro de caixas plásticas. Para a 
quantificação das colônias, empregou-seum retículo calibrado acoplado à lente ocular do microscópio óptico que no aumento de 100 vezes, delimitava-se $100 \mu \mathrm{m}^{2}$ de área, correspondendo a um campo de visualização microscópica. Todas as placas foram quadriculadas com umacaneta deretroprojetor, delimitando-se quadrados de $0,5 \mathrm{~cm}$. Foram destacados 10 quadrados por placa em cujo centro era realizada a contagem. A leitura foi realizada atéo $21^{\circ}$ dia póssemeadura.

As leituras dos tubos foram semanais, até a $6^{a}$ semana, erealizadas deacordo com o critério estabelecido por PINHEIRO (2001).

A pós a padronização das técnicas na diluição $10^{-2}$ o mesmo processamento foi realizadoemamostras de leite nas diluições $10^{-3}, 10^{-4}$ e $10^{-5}$, para avaliação da sensibilidade. Foram realizadas 10repetições decada uma das três diluições e para cada repetição foram semeadas duas placas e dois tubos. Nesta etapa as leituras passaram a serem realizadas até o $14^{\circ}$ dia pós-semeadura,jáquea partir destediao crescimento das colônias começou a tornar difícil a individual ização das mesmas.

Asmedianas decrescimento emU.F.C obtidasnas técnicas 1 (gordura) e 2 (sedimento) foram comparadas, emcada dia deleiturapelo testenão paramétrico deWilcoxon. Paracomparação das técnicas 1 e2ade Petroff, foi utilizado o testenão paramétrico deMannWhitney, por meio do programa Minitab.

\section{RESULTADOSE DISCUSSÃO}

Das três diluições de suspensão bacteriana real izadas com $M$. fortuitum, a diluição $10^{-2}$ foi a que apresentou o melhor padrão de contagem deU.F.C. nas placas contendo meio Middlebrook $7 \mathrm{H} 10$, representando um crescimento de $75 \%$ da superfície da placa no 3o e 5o dia pós-semeadura, micro e macroscopicamente, respectivamente. Esteresultado tambémfoi observado porMARCONDES(2002) utilizan- do a estirpe AN 5 de M . bovis, das diluições feitas a partir da suspensão bacteriana inicial preconizada por PinheIRo (1992).

A escol ha do M . fortuitum, queéumamicobactéria derápido crescimento (KonemAn et al., 2001), fez com que os resultados experimentais fossem obtidos em menor tempo; esta estratégiasebaseou nos trabalhos desenvolvidos por Pinheiro et al (1992) ePinHeIro et al. (1997) que usaram a M . fortuitum na padronização dos parâmetros testes dedesinfetantes, antes deusar a estirpe patogênica $M$. bovis, devido a rapidez na obtenção dos resultados e a possibilidade de se extrapolar oparâmetroobtido paraoutramicobactéria, conforme sugestão do manual da WorLD HEALTH Organization (1984).

O M . fortuitumjáfoi consideradoamicobactéria decrescimento rápido mais comumenteassociada com mastite, tendo sido identi ficada como causadora de mastite porWETZTEIn \& G ReEn FIELd (1992), em 17 casos; isolada em amostras de leite cru proveniente de tanques de armazenamento e tanques transportadores, porDunN \& H ODGSON (1982) e por PARDO et al. (2001), em vacas positivas ou suspeitas ao teste de Stormont, demonstrando a importância de aprimorar os métodos de cultivo de micobactérias para a prevenção de doenças na população.

Reed (1953) e Sommers \& Russell (1967) já relatavamasvantagens deseutilizar meios decultura"agar transparentes"no primo isolamento demicobactérias pois possibilitava a visualização precoce das micobactérias, em média dentro de 10 a 14 dias póssemeadura, atribuindo à técnica de monocamada a precocidade de um diagnóstico positivo, e possibilitando a adição dedrogas em concentrações exatas já queo meio não sofrea ação da temperatura para ficar solidificado.

Os resultados obtidos por meio das 3 técnicas empregadas (técnica 1, 2 e de Petroff tradicional) na diluição $10^{-2}$ dasamostras deleiteexperimentalmente inoculadas, foram resumidos na Tabela 1.

Tabela 1 - Proporções de cultivos com crescimento de micobactérias, segundo a técnica de processamento, o cultivo adotado (tubos e placas) eo momento de leitura.

\begin{tabular}{|c|c|c|c|c|c|c|c|c|}
\hline \multirow[t]{3}{*}{ Técnica } & \multicolumn{4}{|c|}{ Placas positivas/ total } & \multicolumn{4}{|c|}{ Tubospositivos/ total } \\
\hline & \multicolumn{8}{|c|}{ Diaspós-semeadura } \\
\hline & 110 & $14^{\circ}$ & 170 & 210 & 210 & $28^{\circ}$ & $35^{\circ}$ & 420 \\
\hline Petrofftradicional & $25 / 59^{*}$ & $26 / 59$ & $7 / 59$ & 1/ 59 & $6 / 59$ & $37 / 59$ & $15 / 59$ & 1/ 59 \\
\hline Técnica 1 (gordura) & 41/ 58 & 10/ 58 & $7 / 58$ & $0 / 58$ & $13 / 60$ & $32 / 60$ & $15 / 60$ & $0 / 60$ \\
\hline Técnica 2 (sedimento) & $54 / 59$ & $4 / 59$ & 1/ 59 & 0/ 59 & $19 / 55$ & 29/ 55 & $7 / 55$ & $0 / 55$ \\
\hline
\end{tabular}

$*^{\circ}{ }^{\circ}$ depositivos/ no-desemeaduras 
OM . bovis cresceu tantonosmeiosdeMiddlebrook 7H11 modificado quanto no meio de Stonebrink. A mai oria das placas apresentou crescimento no $11^{\circ}$ ou $14^{\circ}$ dia de leitura, para 28 dias apresentados pela maioria dos tubos, sendo que Koneman et al. (2001) citou o tempo médio para o crescimento deamostras de campo como sendo 24 a 40 dias. A adaptação da estirpe ao meio de cultura também explicaria esta precocidade, uma vez que a mesma era mantida em laboratório com sucessivos repiques em meio de Stonebrink.

Corner \& Nicolapoulos (1988) trabal hando com estirpes de $M$. bovis (AN5) e $M$. bovis (M 86/ 90) em diversos meios de cultura, entreeles o deStonebrink e o Middlebrook $7 \mathrm{H} 11$ modificado, obtiveram como médias decrescimento macroscópico, 27,3e 28 dias, respectivamente, para o meio deM iddlebrook. Parao meio deStonebrink as médias foram 32,8 e 30,6 dias, respectivamente.

A técnica 2 apresentou o maior número de cultivos positivos no meio de Middlebrook $7 \mathrm{H} 11$, no 11 으 dia pós-semeadura, primeirodiaemquefoi observado crescimento de colônias. Esta precocidade em relação às demais técnicas empregadas também foi observada para o meio de Stonebrink, que apresentou maior número de cultivos positivos no 21 ㅇ dia pós-semeadura, primeiro dia em quefoi observadoo crescimento.

A técnica tradicional de Petroff foi a que apresentou maior número em dias necessários para o aparecimento das primeiras colônias, nos dois meios empregados.

N a maior parte das placas ocorreu al gum tipo de contaminação, observada em geral logo na primeira leitura. A pesar disto, a maioria das contaminações observadas limitaram-seà região da borda da placa devido ao acúmulo delíquido, não interferindo, portanto, na leitura. $\mathrm{N}$ as placas onde a contaminação estendeu-se por toda a superfície do meio, não foi realizada a contagem de colônias e isto ocorreu em apenas 4 placas. Os resultados das contagens de U.F.C. das placas contendo meio de Middlebrook 7H 11 dastrêstécnicasutilizadasforam resumidosna Tabela 2.

Tabela 2 - Resultado da contagem da média deU.F.C. do M . bovis (estirpeA N5) dototal deplacas, segundo atécnica de processamento adotada, eo momento da leitura.

\begin{tabular}{lcccccc}
\hline Técnica & \multicolumn{5}{c}{ Placas (dias pós-semeadura) } \\
\cline { 2 - 7 } & 30 & 70 & 110 & 140 & 170 & 210 \\
\hline Técnica dePetroff & 0 & 0 & 0,16 & 0,47 & 1 & 1,5 \\
Técnica 1 (gordura) & 0 & 0 & 0,46 & 0,85 & 1,38 & 1,81 \\
Técnica 2 (sedimento) & 0 & 0 & 0,83 & 1,28 & 1,64 & 1,88 \\
\hline
\end{tabular}

Comparando-se as médias de crescimento em U.F.C. das 3 técnicas de processamento empregadas é possível verificar que a média obtida pela técnica de Petroff tradicional foi inferior em todos os dias, à média obtida pelas técnicas 1 e $2 . \mathrm{Na}$ técnica2, foramobtidas asmai oresmédias deU.F.C. em todos os dias de observação; já na primeira observação, esta técnica forneceu uma média de contagem deU.F.C. 5 vezes superior à média obtida pelatécnicadePetroff tradicional $(0,83 e 0,16 U$.F.C. respectivamente) e quase duas vezes superior ao material processado pela técnica 1 (gordura). No 14ํdia pós-semeadura ainda houveuma diferença entre as três técnicas adotadas e só a partir do 17으 diaem diante, diminuiu adiferença entreasmédias de crescimento de U.F.C.

Pelos resultados do teste não paramétrico de Wilcoxon, foi verificada diferença estatística $(\mathrm{P}<$ 0,05 ) entre as medianas de crescimento de U.F.C. obtidas pela técnica 1 e 2 aos 11 e aos 14 dias póssemeadura, sendoestadiferençamaior paraatécnica 2 do quepara 1. A partir do 170 dia, não foi observada diferença estatística entreas medianas decrescimento das placassemeadascommaterial provenientedas técnicas 1 e 2.

O teste não-paramétrico de Mann-Whitney revelou diferença estatística $(p<0,05)$ entreas medianas de crescimento de U.F.C. obtidos pelas técnica 1 e 2 quando comparadas aos resultados da técnica de Petroff tradicional, no 11으, 14으, 170 e 210 dias póssemeadura. Foi possível verificar que o resultado da técnica 2 foi superior aos das demais técnicas empregadas na mesma diluição.

A precocidadeparao aparecimento dasprimeiras U.F.C., observada principalmente nas placas semeadas comatécnica 2, podeser devida ao processo de homogeneização das amostras com $1 \mathrm{~mL}$ de Tween 80, seguida de utilização do aparelho tipo Vortex, por meio do qual foi possível separar as colônias demicobactérias, em consequênciadaaçãofísica aplicadapelo aparel ho edaação detergentedo Tween 80. O Tween 80 , além de nutriente é um agente tensoativo, atua como tal unificando-se à parede lipídicabacilar pelapartehidrofóbicadesuamolécula, eao meio externo pela sua porção hidrofílica (CENTRO PANAMERICANO de Zoonosis, 1979).

A importânciadaforçacentrífuganarecuperação demicobactérias podeser devida ao al to conteúdo de lipídios desua paredecel ular (até40\% do peso seco). Olipídio conferebaixadensidadeao microrganismo. Se o objetivo for a sedimentação máxima de microrgansimo duranteacentrifugação, adensidade dolíquido desuspensão daamostradeveser mantida tão baixa quanto possível, ea força centrífuga aplicada à amostra tão alta quanto prática (KonemAN et al., 2001). 
Tabela 3 - Proporções de cultivos com crescimento de mi cobactérias, segundo a técnica de processamento, o cultivo adotado (placas etubos) ea diluição do inóculo.

\begin{tabular}{|c|c|c|c|c|c|c|}
\hline \multirow[t]{3}{*}{ Técnica } & \multicolumn{3}{|c|}{ Placas positivas/ total } & \multicolumn{3}{|c|}{ Tubos positivos/ total } \\
\hline & \multicolumn{3}{|c|}{ Diluição } & \multicolumn{3}{|c|}{ Diluição } \\
\hline & $10^{3}$ & $10^{4}$ & $10^{5}$ & $10^{3}$ & $10^{-4}$ & $10^{5}$ \\
\hline Técnica de Petroff & $6 / 20$ & $1 / 20$ & $0 / 20$ & $18 / 20$ & $14 / 20$ & $5 / 20$ \\
\hline Técnica 1 (gordura) & $19 / 20$ & $9 / 20$ & $2 / 20$ & $20 / 20$ & $17 / 20$ & $10 / 20$ \\
\hline Técnica 2 (sedimento) & $16 / 20$ & $4 / 20$ & $4 / 20$ & $19 / 20$ & $10 / 20$ & $10 / 20$ \\
\hline
\end{tabular}

*no-de positivos/ no-desemeaduras

KANTOR (1976) trabal hando comamostras desedimentos decentrifugaçãoindustrial deleitecru, provenientes de rebanhos controlados pela prova tuberculínica, obteve62isolamentosdemicobactérias, entre elas duas identificadas como M . bovis.

H OSTY \& M CDURMONT (1975) utilizaramosedimento das amostras deleitecru obtidas de28plantas produtorasdeleite, eobtiveram64isoladosdemicobactérias, em 35 das 51 amostras deleitecru, sendo muitas delas reconhecidas como patogênicas para o homem.

A utilização da gordura no processamento de amostras de leite para isolamento de micobactérias não é usualmente empregada. Perez et al. (2002), investigou a frequência de deteç̧ão de $M$. bovis nas fases de centrifugação do leite proveniente de rebanhos livres da infecção, experimentalmenteinoculado com M. bovis-BCG. O organismo foi isolado do sedimento, mas não foi observado o seu desenvolvimento em amostras de fase aquosa enem gordura.

Trabalhando com leite, foi possível diferenciar microscopicamente a técnica empregada pela observação dos debris. Nas placas semeadas comatécnica 1, se observava o crescimento das U.F.C. em meio a pequenas moléculas degordura; com a técnica tradicional dePetroff, agrandequantidadededebris celulares e de moléculas de gordura tornou difícil a visual ização dasmicobactériasepel atécnica2, quase não se observou a presença de debris. Por meio das Figuras 1, 2e3épossível visual izar ocrescimento das micobactérias processadas pela técnica tradicional de Petroff e pelas técnicas 1 e 2 respectivamente, no meio de Middlebrook $7 \mathrm{H} 11$ modificado.

A técnica2forneceu asmaioresmédiasdeU.F.C.em todosos dias deleitura. Ao contrário, atécnicatradicional dePetroff forneceu as menores médias deU.F.C., provavel mentepelos mesmos fatores já discutidos em relação ao tempo requerido para o aparecimento das primeirascolônias(presençadegrandequantidadede debris celulares, homogeneização ea importância da submissão à forçacentrífuga). A média geral decrescimento nas 3 metodologias tendeu a estabilizar-senos últimos dias de leitura onde a diferença estatística entreas medianas decrescimento não foi significante.

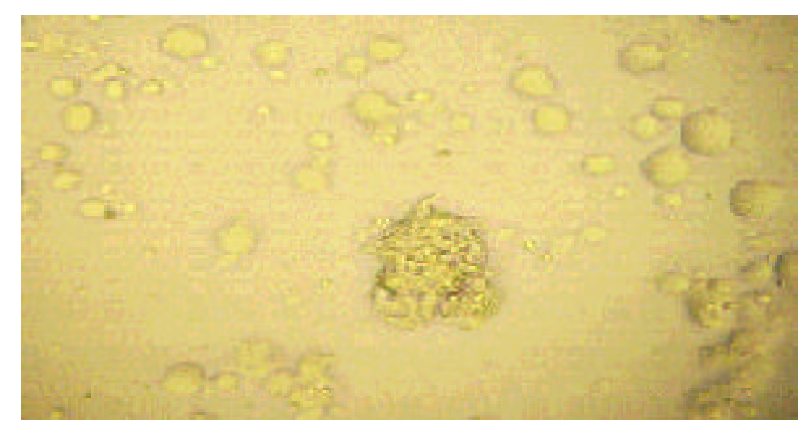

Fig. 1- Colônia deM . bovis aos 14dias decultivo em meio de Middlebrook 7H11 modificado, obtida pela técnica tradicional dePetroff. Visual ização sob microscopiaóptica com aumento de $100 \mathrm{x}$

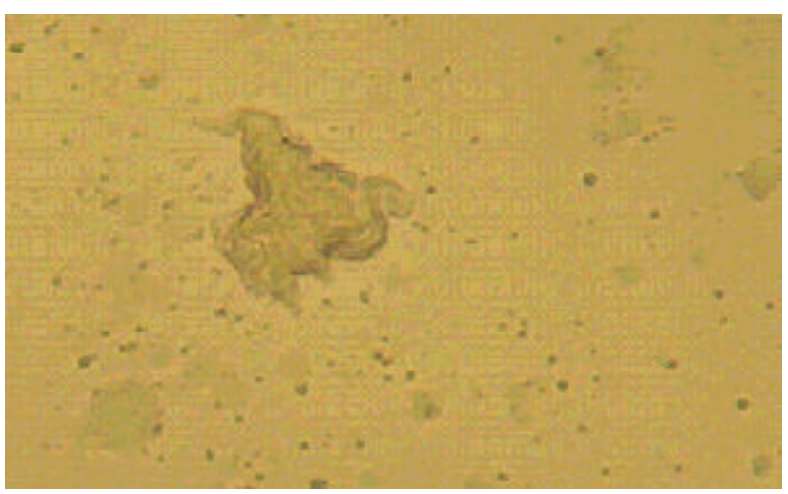

Fig. 2 - Colônia deM . bovis aos 14dias decrescimento, em meio deMiddlebrook $7 \mathrm{H} 11$ modificado, obtidadaTécnica 1 (gordura). Visualização sob microscopia óptica com aumento de $100 x$

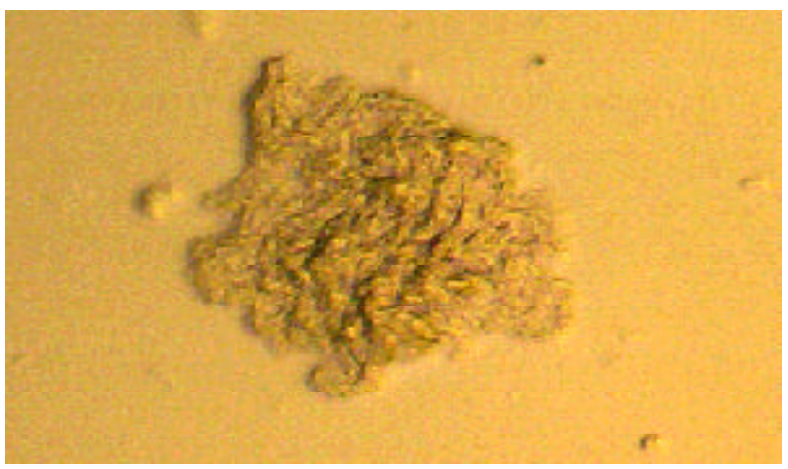

Fig. 3- Colônia deM . bovis com 17dias decrescimento, em meiodeMiddlebrook 7H11,obtidadaTécnica2(sedimento). Visualização sob microscopiaóptica comaumento de 100x 
Poucossão ostrabal hosencontradosnaliteratura que descrevem a metodologia empregada na quantificação das micobactérias. SMITH et al. (2003) avaliaram a técnica de semeadura em espiral pela contagemmicroscópicadascolônias del y ycobacterium paratuberculosis em amostras de leite submetido ao processo deUItraH igh Temperature(UHT) ecompararam as contagens real izadas nos dias 14 e 28 enos dias 8 e 27 pelo Teste t-pareado, não encontrando diferença estatística em nenhum dos casos.

A importância de se utilizar de métodos de diagnóstico de micobactérias em amostras de leite que tenhamumasensibilidademaior consisteno aprimoramento de estratégias de vigilância epidemiológica empregadas em estabelecimentos ligados à produção, armazenamento, distribuição ecomercialização do leite.

Os resultados do crescimento bacteriano nas placas etubos semeados com inócul os nas dil uições 10 ${ }^{3}, 10^{-4}$ e $10^{-5}$ e oriundo do material processado pelas três técnicas anteriormenteestudadas estão apresentados na Tabela 3.

Os resultados desta etapa foram obtidos somente atéo $14^{\circ}$ dia pós-semeadura para as placas eatéo $42^{\circ}$ dia para os tubos tendo em vista que, conforme foi observado nas etapas anteriores a partir 170 dia o crescimento de U.F.C das placas passa a ser macroscópico, e o tamanho das colônias dificulta a visualização de colônias novas.

Pela tabela é possível observar que a técnica 1 (gordura) apresentou em geral, a maior proporção de cultivos positivos nas diluições $10^{-3}$ e $10^{-4}$, nos dois meios empregados. A técnica de Petroff apresentou um número de cultivos positivos no meio de Middlebrook $7 \mathrm{H} 11$ muito inferior aos obtidos nas técnicas 1e2, embora esteresultado não tenha sido o mesmo para o meio deStonebrink, ondea proporção de cultivos positivos foi superior em todas as diluições de todas as técnicas à aquela obtida nas placas. Como foi demonstrado anteriormente, esta técnica apresentou um crescimento mais lento e um menor número de colônias recuperadas frente às técnicas 1 e 2, este fato que somado a técnica de quantificação empregada, onde são visualizados apenas $10 \mathrm{cam}$ pos microscópicos, podem ter influído com a baixa porcentagem de positivos eausência de crescimento nas demais diluições.

A pesar da diminuição no número de dias necessários para o isolamento de $M$. bovis no meio de Middlebrook $7 \mathrm{H} 11$ a proporção decultivos positivos apresentada pelo meio de Stonebrink nesta etapa, foi superior em todas as diluições à proporção de placas positivas obtidas no meio de Middlebrook. Estes resultados sustentam as afirmações dos autores MarCondes (2002) eCoRner \& Nicolacopoulus (1988), de que o método de Middlebrook $7 \mathrm{H} 11$ modificado deveser utilizado simultaneamente com os métodos tradicionais de cultivo.

Cousins et al. (1989) observaram que, apesar da precocidadeem dias parao isolamento doM . bovisno meio deMiddlebrook 7H 11 modificado, o número de colônias recuperadas foi inferior aos outros 4 meios empregados (2variações do meio deStonebrink; meio deLöwenstein-Jensen eB83). Esteresultado poderia ser um dos fatores a explicar a menor proporção de cultivos obtidos no meio deM iddlebrook 7H 11 nesta etapa do experimento, onde foram empregados inóculos mais diluídos.

O método de contagem padronizado na segunda etapa deste experimento, podeter dificultado a detecção decolônias deM . bovisquandoempregado para a leitura das placas semeadas com inócul os em diluições maiores, já que se limitando o número de campos microscópicos e o espaço necessário para a visualização das colônias, limita-sea probabilidade de encontrá-las pela superfície do meio de cultura, diminuindo destamaneira, as chances deseobter um diagnóstico positivo, o que dificilmente acontece no meio de Stonebrink onde o espaço delimitado para quantificação das colônias foi mais abrangente.

A restrição do tempo para apenas duas semanas, também pode ser um dos fatores responsáveis pela baixa sensibilidade encontrada no meio de Middlebrook 7H 11 em relação ao meio deStonebrink (Tabelas 4, 5 e 6). Corner \& Nicolacopoulos (1988) realizaram a contagem macroscópica das col ôniase mesmo desta maneira ainda conseguiram demonstrar diferençaem dias parao primeiro isolamento, em relação aos métodos tradicionais.

A superioridade observada das técnicas 1 e $2 \mathrm{em}$ relação à técnica de Petroff tradicional, para recuperação de colônias de M . bovis de amostras de leitein natura, eaprecocidade do meio deM iddlebrook $7 \mathrm{H} 11$ modificado em relação ao meio de Stonebrink, demonstram a possibilidade de sua utilização como método complementar para o isolamento de micobactérias no leite. Devido às dificuldades observadasnacontagemmicroscópicadecolônias nomeio de Middlebrook, há a necessidade de serem realizadosmaisestudosparao aprimoramento destatécnica em relação à sua sensibilidade.

\section{CONCLUSÕES}

Astécnicas 1 (gordura) e2 (sedimento) forammais sensíveisfrenteà técnica dePetroff tradicional aos 14 dias de crescimento. O meio de Middlebrook $7 \mathrm{H} 11$ modificado permitiu a visualização precoce das micobactérias quando comparadas aos meios de Stonebrink, e portanto pode ser utilizado como uma técnica complementar aos métodos tradicionais de 
diagnóstico da tuberculose bovina em amostras de leite para fins de vigilância epidemiológica.

\section{REFERÊNCIAS}

Antunes, J.L.F.; Moraes, M.; Bazevic, M.G.H.; Waldman, E.A.; CorrêA, M.O.A. Tuberculose e leite:elementos para a história de uma polêmica. História, Ciências, Saúde - M anguinhos, v.9, n.3, p.609-623, 2002.

BRANDÃo, S.C.C. Leite: legislação, responsabilidadeesaúde pública. Balde Branco, v.30, n.360, p.68-71, 1994.

Centro Panamericano de Zoonosis Bacteriología de la tuberculosis humana y animal. Buenos Aires: Organización Panamericana dela Salud, 1979. 63p.

CORnER, L.A. Postmortem diagnosis of M ycobacteriumbovis infection in cattle. V eterinary M icrobiology, v.40, n.1-2, p.53-63, 1994.

CoRner, L.A. \&Nicolapoulos, C. Comparison of mediaused for the primary isolation of $M$ ycobacterium bovis by veterinary and medical diagnostic laboratories. A ustralian V eterinary Journal, v.65, n.7, p.202-204, 1988.

CousinsD.V.; Francis, B.R.; Gow, B.L. A dvantages of anew agar medium in theprimary isolation ofM ycobacterium bovis. Veterinary M icrobiology, v.20, n.1, p.89-95, 1989.

Dunn, B.L. \& Hodgson, D.J. "Atypical" mycobacteria in milk. Journal of A pplied Bacteriol ogy, v.52, n.3, p.373-376, 1982.

Hostr, T.S. \& McDuRmont, C.I. Isolation of acid-fast organisms from milk and oyters. Health Laboratory Science, v.12, n.1, p.16-19, 1975.

KANTOR, I.N. Micobacterias aisladas de muestras deleche em Buenos A ires, A rgentina. R evista A rgentina Tuberculose. y Enfermidades Pulmonares, v.37, n.1/ 4, p.57-59, 1976.

Koneman ,E.W.;A llen, S.D.;L anda, W.M.;SchreckenberGer, P.C.; Winn JUnIOR, W.C. Diagnóstico microbiológico. TeXto e atlas colorido. 5.ed. Rio de Janeiro: Editora M edsi, 2001. 1465p. Capítulo 17 Micobactérias.

Leite, C.Q.F.; Anno, I.S.; Leite, S.R.A.; Roxo, E.; Morlock, G.P.; COOKSEY, R.C. Isolation and identifaction of Mycobacteria from livestock specimens and milk obtained in Brazil.M emórias do I nstituto 0 swal do Cruz, v.98, n.3, p.319-323, 2003.

MARCondes, A.G., Padronização da técnicadecultivo em camada delgada de agar M iddlebrook 7H 11 para isolamento de M ycobacterium bovis. 2002. 115p.Dissertação (Mestrado) - Faculdade de Medicina Veterinária e Zootecnia, Universidade deSão Paulo, São Paulo, 2002.

Mejia, G.I.; Castrilloon, I.; Trujillo, H.; Robledo, J.A. Microcol ony detection in 7H 11Thin layer cultureisna alternative for rapid diagnosis of $M$ ycobacterium tuberculosis infection. International J ournal of T uber culosis and Lung Disease, v.3, n.2, p.138-142, 1999.
PARDo, R.B.; Langonı, H.; Mendonç,A,I.J.P.;C HI, K.D.Isolation of Mycobacterium spp. in milk from cows suspected or positivetotuberculosis.Brazilian Journal of V eterinary Research and A nimal Science, v.38, n.6, p.284-287, 2001.

Perez, A., Reniero, A.; Fortels, A.; Meregalli, S.; López, B.; RItAcco, V. Estudio deM ycobacteriumbovisen leche mediante métodos bacteriológicos y reacción en cadena de la polimerasa. Revista Argentina de M icrobiologia, v.34, n.1, p.45-51, 2002.

Pinheiro, S.R.; Vasconcellos, S.A.; Ito, F.H.; Ferreira Neto, J.S.; MorAIs, Z.M. Influência da matéria orgânica na atividade micobactericida de cinco desinfetantes de uso pecuário. Brazilian Journal of V eterinary Research and A nimal Science, v.29, n.1, p.51-60, 1992.

Pinheiro, S.R.; Vasconcellos, S.A.; Morais, Z.M.; Ferreira Neto, J.S.; SIn horinI, I.L.; Ito, F.H.; CÔRTES, J.A. Padronização deteste “in vitro" paraa avaliação daatividademicobactericida do hipoclorito de sódio edeuma combinação de aldeídos. Influência da passagem da estirpeteste( $M$ y cobacteriumbovis - AN5) emhamsters. A rquivos do Instituto Biológico, São Paulo, v.64, n.1, p.1122, 1997.

PINHEIRo, S.R. A valiação da atividade mi cobactericida de desinfetantes químicos sobre estirpes de M y cobacterium avium isol adas desuínos abatidos no estado de Santa Catarina, no an o de 1999. 2001, 91p. Tese (LivreDocência) - FaculdadedeM edicina Veterinária eZootecnia, Universidade de São Paulo, São Paulo, 2001.

REED, R.W. Slideculture of tuberclebacilli.Canadianjournal of M edicine Science, v.31, n.5, p.367-376, 1953.

SMITH, W.L.; McGaRVEY, K.L.; C ULLOR, J.S. The use of spiral plating and microscopiccolony couting for therapid quantitation of $\mathrm{M}$ ycobacterium paratuberculosis. Letters in A pplied M icrobiology, v.36, n.5, p.293-296, 2003.

SMOSKÖVI,A.\&M AGYAR, P.Comparison of themycobacterial growth indicator tube with MB Redox, Löwestein Jensen, and Middlebrook $7 \mathrm{H} 11$ mediafor recovery of mycobacteria in clinical specimens. Journal of Clinical M icrobiology, v.37, n.5, p.1366-1369, 1999.

SOMmers, H.M. \& RusseL, J.P. Description of clinically significant mycobacteria. In:SOMmers, H.M. (Ed.).The clinically significant mycobacteria: recognition and identification. Chicago: American Society of Clinical Pathologists, 1967. p.3-15.

Wetzstein, M. \& Greenfield, J. Mastitis caused by a M ycobacterium sp. Canadian Veterinary Journal, v.33, n.9, p.826, 1992.

World Health Organization Guidelines on desinfection in animal husbandry for prevention and control of zoonotic diseases. Geneva:WHO, 1984.49p.(WHO/ VPH/ 84.4).

Recebido em 5/ 4/ 06

A ceito em 1/ 6/ 06 